\title{
GAME OVER: A GESTÃO GAMIFICADA DO TRABALHO
}

\author{
Recebido em 31/03/2021, aprovado em 5/05/2021 \\ 10.30612/mvt.v8i14.15018 \\ Viviane Vidigal'
}

RESUMO: A gamificação - prática de aplicar mecânicas e características de jogos para engajar e motivar comportamentos - se tornou um dos fenômenos debatidos nos estudos dedicados a entender a constituição do trabalho contemporâneo. Este artigo tem como escopo problematizar a gestão gamificada do trabalho. A hipótese sustentada é a de que, trata-se de uma linguagem para emular a intensificação do trabalho e o aumento da produção, em um ambiente controlado por algoritmos. Desta forma, a gamificaçáo pode ser compreendida como um modelo de premiar e punir o(a) trabalhador(a) que atinge ou não uma meta imposta pelas empresas, desvelando-se como mecanismo de gestão para interferir na vontade do(a) trabalhador(a), ao incutir o desejo de trabalhar mais. Para construir os argumentos, serão apresentados dados empíricos, recolhidos de pesquisas qualitativas desenvolvidas a partir da observaçáo direta, da análise de documentos e da realizaçáo de entrevistas semiestruturadas com trabalhadores(as) de plataformas digitais da região metropolitana de Campinas e São Paulo (SP). As entrevistas realizadas articuladas à bibliografia sobre o tema demonstrarão se a estratégia de mobilizar a dimensão afetiva dos(as) trabalhadores(as) através da gamificação está sendo ou não exitosa, esmiuçando argumentos que visam compreender como os aspectos gerenciais são internalizados pelos(as) trabalhadores(as) plataformizados(as).

Palavras-chave: Gamificação. Gestão. Trabalho.

\section{GAME OVER: GAMIFICATION OF LABOR}

ABSTRACT: Gamification - the practice of applying mechanics and characteristics of games to engage and motivate behaviors - has become one of the phenomena discussed in studies dedicated to understanding the constitution of contemporary work. This article aims to discuss the gamified work management. The supported hypothesis is that it is a language to emulate the intensification of work and the increase in production, in an environment controlled by algorithms. Gamification might be understood as a model of rewarding and punishing workers who achieve or fail a goal imposed by companies, revealing the management mechanism to interfere in the worker's will, by instilling the desire to work more. To build the arguments, empirical data collected from qualitative research and developed from direct observation, as well as document analysis and semi-structured interviews with workers from digital platforms in the metropolitan region of Campinas and São Paulo (SP) will be presented. The interviews carried out in conjunction with the bibliography on

1 Professora e pesquisadora. Doutoranda e mestra em Sociologia pela Universidade Estadual de Campinas (UNICAMP), orientada pelo professor Dr. Ricardo Antunes. Integrante do grupo Grupo de Pesquisa Mundo do Trabalho e suas Metamorfoses (GPMT). Pós-graduada em Direito do Trabalho (UNISAL). Email: v192482@dac.unicamp.br. 
the topic will demonstrate whether the strategy of mobilizing the affective dimension of workers through gamification is successful or not, examining arguments that aim to understand how managerial aspects are internalized by platform workers.

Keywords: Gamification. Management. Labor.

\section{JUEGO TERMINADO: GESTIÓN DEL TRABAJO CON JUEGOS}

RESUMEN: Gamificación - la práctica de aplicar mecánicas y características de los juegos para involucrar y motivar comportamientos -, se ha convertido en uno de los fenómenos discutidos en los estudios dedicados a comprender la constitución del trabajo contemporáneo. Este artículo tiene como objetivo discutir la gestión del trabajo gamificado. La hipótesis sustentada es que se trata de un lenguaje para emular la intensificación del trabajo y el aumento de la producción, en un entorno controlado por algoritmos. Puede entenderse como un modelo de recompensa y castigo al trabajador que alcanza o no una meta impuesta por las empresas, revelando el mecanismo de gestión para interferir en la voluntad del trabajador, inculcando el deseo de trabajar más. Para construir los argumentos, se presentarán datos empíricos, recolectados de investigación cualitativa, desarrollados a partir de observación directa, análisis documental y entrevistas semiestructuradas con trabajadores de plataformas digitales en la región metropolitana de Campinas y São Paulo (SP). Las entrevistas realizadas en conjunto con la bibliografía sobre el tema demostrarán si la estrategia de movilizar la dimensión afectiva de los trabajadores a través de la gamificación es exitosa o no, examinando argumentos que pretenden comprender cómo los aspectos gerenciales son internalizados por los trabajadores de la plataforma.

Palabras Clave: Gamificación, Gestión, Trabajo.

\section{INTRODUÇÃO}

Em protesto à queda da remuneração no contexto da pandemia, entregadores(as) do município de São Paulo fizeram uma manifestação na avenida Paulista, no dia primeiro de julho de 2020. Uma da queixas mais ouvidas no protesto é que os bônus e prêmios que as empresas ofereciam para os(as) entregadores(as) deixaram de existir em um momento em que eles(as) enfrentam um risco maior na realização do trabalho, em decorrência do novo coronavírus (PEREIRA, 2020). Um levantamento feito pela Rede de Estudos e Monitoramento da Reforma Trabalhista (Remir Trabalho) ${ }^{2}$ em quatro estados brasileiros, indicou que quase $50 \%$ dos respondentes da pesquisa apontaram uma queda no bônus concedido pelas empresas-plataforma de entrega (ABÍLIO et al., 2020). Os(as) motoristas de Uber também relataram que esses bônus e incentivos sumiram (RIBEIRO, 2020).

Esses bônus são resultado de desafios em forma de jogos que os entregadores deveriam cumprir para aumentar seus ganhos. Este é um modelo de premiar o(a) trabalhador(a) que atinge uma meta imposta pela empresa e revela o mecanismo de gestão de incutir nos(as) trabalhadores(as) o desejo de trabalhar mais, desvelando-se o mecanismo psicológico de interferir em sua vontade, forçando a intensificação do trabalho e o aumento da produção (VIDIGAL, 2020).

No contexto pandêmico, podemos entender que as bonificaçôes diminuíram porque se no "antigo normal” era necessário um maior estímulo para manter os(as) trabalhadores(as) engajados(as), 
com o isolamento social, o aumento de trabalhadores(as) nas plataformas ${ }^{3}$ e aumento de pedidos pelos(as) consumidores(as), as empresas não precisam se preocupar em estimular o trabalho como no período anterior. Ainda, a lógica principal que captura a subjetividade desses(as)trabalhadores(as) (ALVES, 2010) é a da sobrevivência. Dessa forma, verificaremos como as empresas se valem do mecanismo de gestão gamificada de acordo com as suas necessidades e interesses.

A hipótese sustentada é a de que a gestão gamificada do trabalho é uma linguagem para emular a intensificação do trabalho e aumento da produção em um ambiente controlado por algoritmos. Esmiuçaremos argumentos que visam compreender como os aspectos gerenciais são internalizados pelos(as) trabalhadores(as) plataformizados(as), destacando os aspectos centrais da gamificação do trabalho plataformizado, como preço dinâmico, desafios, bonificaçôes e promoçóes.

O artigo está estruturado, para além da introdução, da seguinte forma: na primeira parte, será apresentado o conceito de gamificaçáo. A segunda parte abordará a gestáo gamificada do trabalho e as expressóes concretas do trabalho gamificado, tomando como exemplos as práticas dos(as) trabalhadores(as). Na terceira parte, problematizaremos qual é a novidade desse modelo de gestão do trabalho. Na quarta parte, será abordado como o novo pede o velho, expondo o salário por peça e sua imbricação com a gamificação. A última parte estabelece consideraçôes finais.

\section{NOTAS METODOLÓGICAS}

Os dados aqui apresentados são fruto de duas pesquisas: uma concluída e outra em andamento. A primeira, intitulada As ilusóes da uberização: um estudo à luz da experiência de motoristas Uber, foi realizada entre março de 2017 e dezembro de 2019 e contou com entrevistas semi-estruturadas de 22 pessoas: 19 homens e três mulheres, motoristas de UberX $\mathrm{X}^{4}$ nas cidades de Campinas (SP) e São Paulo (SP). A segunda, intitulada Profissão Aplicativo: a plataformização do trabalho feminino, foi iniciada em março de 2020. As entrevistas estão em andamento e o estudo tem com objeto motoristas da Uber, motoristas da Lady Driver ${ }^{5}$, entregadores(as) de comida do iFood e manicures da Singu $^{6}$, nas cidades de Campinas (SP) e São Paulo (SP). Para este artigo, contaremos com excertos das entrevistas realizadas na pesquisa concluída. Os nomes apresentados são fictícios e seguem o acordo de anonimato firmado entre entrevistados(as) e a pesquisadora. Também contaremos com a etnografia realizada em grupos de Facebook e Whatsapp, na segunda pesquisa. O artigo destaca e se aprofunda no caso dos(as) motoristas de transportes Uber, ressalvando ser necessário o avanço na análise da gamificação para outras categorias, que traremos de forma apendicular.

\section{START: 0 QUE É GAMIFICAÇÃO}

Brincadeira e trabalho podem ser compreendidos, por alguns autores, como opostos: "brincar é improdutivo, o trabalho é produtivo, brincar é gratuito, o trabalho é oneroso, brincar entretém, o trabalho não tem esse propósito" (SAVIGNAC, 2017, p. 30). A esse despeito, apresentam-se iniciativas que imbricam o jogo com o trabalho. Como funciona essa associação?

3 O iFood, que opera em mais de 1 mil cidades em todo o Brasil, recebeu em março 175 mil inscriçóes de pessoas interessadas em atuar como entregadores da plataforma ante $85 \mathrm{mil} \mathrm{em} \mathrm{fevereiro.} \mathrm{Informação} \mathrm{disponível} \mathrm{em:} \mathrm{https://economia.uol.}$ com.br/noticias/reuters/2020/04/01/candidatos-a-entregador-do-ifood-mais-que-dobram-apos-coronavirus.htm. Acesso em 25 de maio de 2020.

4 A principal e mais usada opção da Uber, o UberX oferece viagens com preços acessíveis em carros compactos de quatro portas e ar-condicionado. Presente em todas as cidades brasileiras onde a Uber opera. Informaçáo disponível em: https://www. uber.com/pt-BR/blog/categorias-da-uber/.

5 Aplicativo de transporte que conecta passageiras e motoristas mulheres. https://ladydriver.com.br/.

6 Empresa aplicativo de profissionais da beleza. Cerca de 200.000 clientes cadastrados. Mais de 3.000 profissionais. https://singu.com.br/. 
O jogo permanece até hoje um assunto complexo a ser abordado nas ciências humanas e sociais, devido à polissemia do termo. Um jogo pode ser definido por um sistema no qual os jogadores participam de um ambiente artificial, definido por regras e estratégias, que geram um resultado quantificável (SALEN; ZIMMERMAN, 2004).

O termo gamificação (do inglês gamification) originou-se na indústria de mídias digitais. Por ser uma nova área de estudo, a definição de gamificação ainda náo é completamente consolidada, no entanto, uma das mais aceitas atualmente é definida por Deterding: "Gamification é o uso de elementos de design de jogos em contextos que não são relacionados a jogos” (DETERDING et al., 2011). Segundo o autor, a palavra jogo (do inglês game) significa algo que é caracterizado por regras e possui uma competição para alcançar resultados específicos ou metas definidas por participantes humanos (DETERDING et al., 2011).

A gamificação também pode ser entendida como uma adaptação de atividades e serviços sob um formato de jogo (KIRKPATRICK, 2015), incorporando-se a serviços já existentes características ou qualidades que proporcionem experiências lúdicas e significativas para os seus usuários, a partir do uso de elementos e técnicas já utilizadas em jogos (HUOTARI; HAMARI, 2012). Diferentemente dos videogames, a gamificação, como gestão do trabalho, não busca apenas simular uma realidade, mas também influenciá-la (WERBACH, 2016). Sublinha Marie-Anne Dujarier (2015) que fazer um jogo do próprio trabalho pode consistir em produzir "uma construção coletiva de uma certa 'realidade', útil para alcançá-la”' (DUJARIER, 2015).

Emmanuelle Savignac (2017) oferece ao leitor um valioso material para pensar a questão do brincar nas organizaçóes do trabalho, tanto por meio do arcabouço teórico mobilizado quanto pelo corpus de sua investigação sobre os usos gerenciais do jogo. Um aspecto observado por Savignac é que "a gamificaçáo por meio de jogos de papéis e simulação permitiria que o mundo profissional fosse colocado em ordem por regras e padrões naturalizantes” (SAVIGNAC, 2017, p. 138, tradução livre) ${ }^{7}$.

O ambiente gamificado, por meio de jogos de papéis e simulação, pode ser criado para moldar os(as) trabalhadores(as) a fim de atender aos padróes exigidos pelas empresas. A Uber, por exemplo, criou o chamado "Desafio Cinco Estrelas". O game se passa na cidade de Uberlândia e traz três módulos com desafios à espera de solução: qualidade básica, qualidade avançada e direção defensiva. A ideia, de acordo com a empresa, é instruir os(as) motoristas sobre como agir enquanto transportam um(a) passageiro(a) e também dar dicas sobre direção e manutenção do veículo. A ferramenta é destinada náo apenas aos(as) novatos(as), mas também aos(as) motoristas com avaliação abaixo da média da cidade na qual dirigem.

As mudanças de comportamento dos(as) trabalhadores(as) seriam resultado do processo de gamificação (KAPP, 2012). A iniciativa da gamificação, em contexto laboral, tem como escopo principal engajar o(a) trabalhador(a). O engajamento refere-se ao quão envolvido e entusiasmado(a) ele(a) está em utilizar o sistema, aumentando seu acesso e participação. Com a utilização de gamificação é possível fazer que as metas sejam atingidas, como por exemplo, com a utilização de desafios e missóes que podem deixar o sistema mais desafiador. Assim como os pontos e conquistas podem trazer o sentimento de diversão, há a necessidade da presença do aspecto lúdico, divertido nos jogos, conforme destacada em Huizinga (1949) e Ryan et al. (2006). Os autores sustentam que, nos jogos,

$7 \quad$ Texto original: "la gamification par le jeu de rôles et le jeu de simulation permettrait une mise en ordre du monde professionnel par la naturalisation des règles et des normes." 
o prazer emerge a partir do aprimoramento da capacidade de autonomia na tomada de decisóes. Malaby (2007), por outro lado, indica que os jogos náo precisam ser essencialmente "divertidos" para serem jogados: basta que sejam instigadores e envolventes a ponto de engajar o sujeito. Ferrara (2013), analisando especificamente o caso de dos jogos eletrônicos, indica que a motivação dos jogadores estaria associada, na maioria das vezes, a uma vontade de vencer.

Dessa maneira, os(as) participantes podem se envolver por conta da diversão da experiência, ou ainda por visualizarem "distinçôes", em relação a um trabalho "sério", ou mesmo por sentirem uma compulsão ao "chamado" do ambiente gamificado que mobiliza fatores psicológicos a partir de comparaçôes sociais ou recompensas (WERBACH, 2016). As recompensas consistem poderoso elemento motivacional, frequentemente aplicado à gamificação, usualmente associadas à conclusão de tarefas, desafios intrigantes, instigantes ou incomuns.

É importante que os elementos utilizados na gamificação sejam significativos para os(as) trabalhadores(as), tal qual sinalizado em Deterding et al. (2011), e que as escolhas apresentadas sejam consideradas como relevantes para os(as) participantes (FERRARA, 2013). Os elementos de jogos mais utilizados nas gamificaçóes são os pontos (Points), as insígnias (Badges) e os quadros de liderança (Leaderboards). Quando considerados conjuntamente, estes componentes compóem uma mecânica denominada PBL, uma estratégia de gamificação bastante popular, identificada em Werbach e Hunter (2012). No sistema Uber, temos exemplos de dois elementos citados, que podem ser visualizados a partir da figura abaixo:

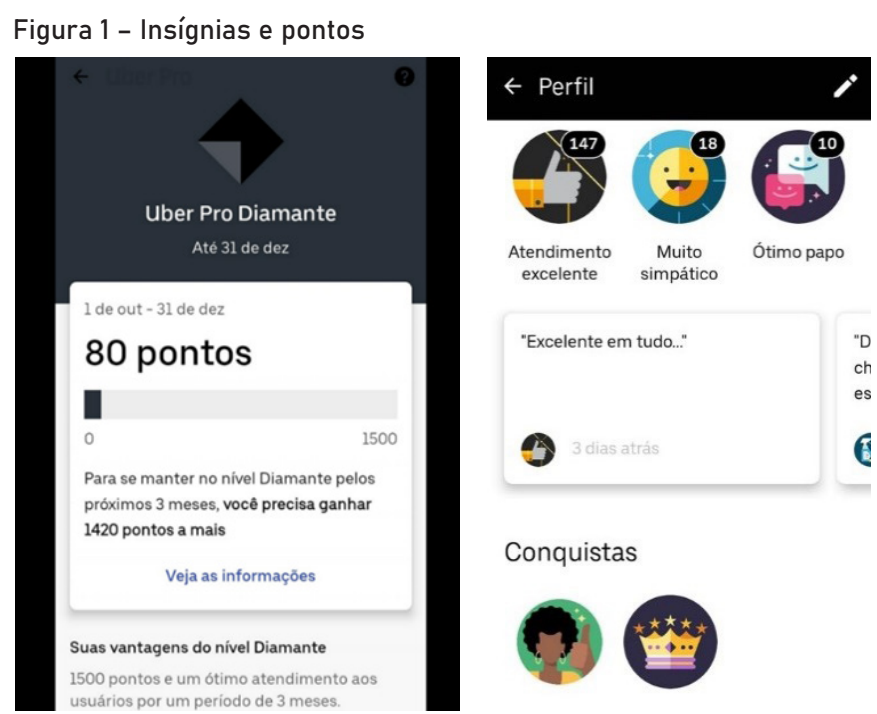

Fonte: Entrevistado da pesquisa "As ilusões da uberização".

Empresas como a Uber apresentam padrôes gamificados de engajamento do(a) trabalhador(a) (STARK, 2016, p. 3759) com “missóes”, "insígnias”, desafios, promoçôes, preço dinâmico, bonificaçôes em dinheiro, além de outros elementos que seriam usados para manter os(as) condutores(as) nas ruas por mais tempo, intensificando o trabalho e aumentando a produção. Como apontado por Kirkpatrick (2015), essa transformação da atividade em jogos busca ampliar a sua performance, ou seja, torná-las mais atrativas e intensificar a produção. Advertem Santos e Ferreira (2008) que a caracterização de uma atividade como jogo acaba por legitimar a sua precarização, o que dificulta um reconhecimento dela como forma de trabalho. Ressaltam os autores que o que se sucede "não 
é o fim do trabalho, mas sim a sua intensificação, por uma distribuição mais eficiente" (SANTOS; FERREIRA, 2008, p. 92).

No contexto deste artigo, a gamificação - incorporação de elementos e técnicas de jogos para outros fins (DETERDING, 2011) - pode ser entendida como uma tentativa do capitalismo de integrar, ao âmbito do trabalho uma dimensão afetiva, que concerne o fator da diversão para um apagamento do sofrimento no trabalho, e uma dimensão material, pois ao completar os desafios os trabalhadores aumentam os seus rendimentos. Como consequências da gamificação existem ganhos simbólicos e materiais, positivos ou negativos, destinados aos(as) trabalhadores(as).

\section{GESTÃO GAMIFICADA DO TRABALHO}

Para compreendermos como se opera a gestão gamificada do trabalho, demonstraremos como o trabalho se organiza por plataformas, entrelaçado à ausência de uma rede de proteção trabalhista e social. Os(as) trabalhadores(as) estão vinculados às empresas platafomizadas por contrato de adesão.

É possível compreender o trabalho plataformizado como um ecossistema envolvendo um conjunto de actantes, ou seja, atores humanos e não humanos, empresas, plataformas, usuários/ consumidores, Estado, algoritmo, programas de rastreamento, banco de dados, entre outros dispositivos. As plataformas "são infraestruturas digitais que possibilitam a interação entre dois ou mais grupos" (SRNICEK, 2017, p. 43).

A tecnologia da informação e comunicação permite às plataformas terem acesso a um grande contingente de trabalhadores sem a necessidade de contato direto, determinando as regras do negócio e verificando o desempenho do trabalho pelas notas dadas pelos usuários. O algoritmo, a partir de todas as informações que lhe são apresentadas, é capaz de organizar toda a atividade (REIS; CORASSA, 2017).

O gerenciamento algorítmico é prática gerencial fundamental na implementação da gamificação desse trabalho, podendo ser definido como supervisão, governança e práticas de controle conduzidas por algoritmos de software sobre trabalhadores (MÖHLMANN; ZALMANSON, 2017). No modelo trabalhista plataformizado, o controle e avaliação da atividade laboral se dá em duas esferas que atuam de forma conjunta e simultânea, compondo o sistema gerencial: o algoritmo e a multidão de gerentes invisíveis ${ }^{8}$.

Por meio das narrativas dos(as) trabalhadores(as) plataformizados(as), podemos constatar que a forma de contratação não possibilita nenhuma previsibilidade em relação ao número de horas trabalhadas e nem à remuneração, pois tais trabalhadores(as) receberão apenas pelas horasefetivamente laboradas; trabalham por demanda e metas ${ }^{9}$ a cumprir; a precificação é feita pela empresa; as jornadas podem ser extensas e intensas; o tempo que dedicam à atividade pode ser permeado por outras atividades; não há garantia de um salário mínimo, nem de adicionais salariais; os intervalos interjornada e intrajornada são gestados por eles(as); as férias, quando existentes, não são remuneradas; pode ocorrer extinção unilateral dos contratos pelas plataformas, sem apresentar maiores explicaçóes; a contribuição ao fundo previdenciário é individualizada e incerta, podendo comprometer a perspectiva de aposentadoria (VIDIGAL, 2020). Além dessa intensa exploração, soma-se,

8 "Gerentes invisíveis" são os(as) consumidores(as), que dão nota ao serviço prestado.

9 As metas são pré-determinadas pelo(a) próprio(a) trabalhador(a), que só para de trabalhar quando atingir tais metas. 
segundo Antunes (2020), uma forte espoliação, presente quando os(as) trabalhadores(as) arcam com as despesas de compra dos veículos, motos, carros, celulares, cortadores de unhas, alicates e suas respectivas manutençôes, dentre outros equipamentos de trabalho.

Na proposta deste artigo, é essencial observarmos o fato de que o trabalho plataformizado está associado ao(a) trabalhador(a) integralmente disponível ${ }^{10}$ para o trabalho, à conformaçáo do(a) trabalhador(a) just-in-time $e^{11}$, isto é, um(a) trabalhador(a) sob demanda (ABÍLIO, 2020). A exigência de performance atendendo aos interesses do capital cujo propósito natural é o de funcionar como impulso para mais acumulação produz um(a) trabalhador(a) ideal que não para nunca: aquele(a) sempre disposto(a) e disponível.

Para compreender as jornadas intensas e extensas desses(as) trabalhadores(as), devemos considerar a gamificação pela qual as empresas buscam mantê-los(as) conectados(a) pelo maior tempo possível, sobretudo nos locais, dias e horários que eles(as) têm mais interesse, ou seja, quando há diminuição de trabalhadores(as) disponíveis: feriados, finais de semana, dias chuvosos, horários noturnos. Em matéria publicada na Folha de S. Paulo, baseada em reportagem do jornal americano New York Times, a gamificação foi abordada da seguinte forma:

Empregando centenas de cientistas sociais e especialistas em dados, o Uber testou técnicas de videogames, recursos gráficos e recompensas não monetárias de baixo valor capazes de estimular os motoristas para que trabalhem mais - e ocasionalmente em lugares e horários que são menos lucrativos para eles. (...) A Uber resolve esse problema fundamental por meio de técnicas de persuasão psicológica e outros métodos desenvolvidos pelas ciências sociais com o objetivo de influenciar quando, onde e por quanto tempo seus motoristas trabalham (SCHEIBER, 2017, online).

A empresa, como técnica, procura encorajar os(as) motoristas a se dirigirem às áreas de escassez (SCHEIBER, 2017). Uma dessas técnicas é "preço dinâmico", descrito pela empresa como "um algoritmo que calcula automaticamente a oferta e a demanda por carros para determinar o valor mais adequado para equilibrar a balança. Dessa forma, os motoristas parceiros não podem induzir o preço dinâmico ficando online ou offline" (UBER, 2020, online). Seguindo regras de um mercado liberal, "o que move o preço dinâmico é o equilíbrio entre a oferta de motoristas e a demanda de usuários pelo serviço (UBER, 2020, online).

Pode-se identificar, pelo excerto de entrevista abaixo, como a cobrança é estabelecida pelo preço dinâmico, o que faz com que a tarifa flutue durante momentos de alta demanda: quando há mais usuários solicitando viagens do que motoristas disponíveis, o preço da corrida subirá. Quando o movimento cai e o número de passageiros é igual ou menor do que o de motoristas, a tarifa volta a cair até atingir o preço normal. Segundo a Uber, a alteração funciona como uma forma de incentivar motoristas a estarem disponíveis em horas de maior demanda.

\footnotetext{
10 Richard Sennett (2003) já se referia à ideia de disponibilidade integral em $A$ corrosão do caráter, ao relatar a história de Rico, um trabalhador que atuava em contrato flexível, fazendo contraposiçáo ao taylorista-fordista.

11 Pode ser traduzido livremente como "na hora certa" ou "no momento exato". Concebido no Japão, em oposição ao just-in-case fordista, tem se difundido pelo mundo nas últimas décadas, juntamente com outros aspectos do Toyotismo. "Just-in-time significa que, em um processo de fluxo, as partes corretas necessárias à montagem alcançam a linha de montagem no momento em que são necessárias e somente na quantidade necessária. Uma empresa que estabeleça esse fluxo integralmente pode chegar ao estoque zero" (OHNO, 1997, p. 26).
} 
V.V.C: A empresa nunca faz sugestôes de locais?

Bruno: Eles mandam sugestóes quando sabem que vai ter evento com alta demanda, tipo sábado vai ter show de tal no lugar tal, mas só como sugestão. Não tem obrigatoriedade de ir até o local.

V.V.C: Por que lá está em taxa dinâmica? Como ela funciona?

Bruno: Segundo informaçôes do aplicativo, funciona por demanda... Se tem uma demanda muito alta e não muitos motoristas, eles aplicam o preço dinâmico para chamar motorista pra lá. Pra gente só aparece avermelhada no mapa as regiōes que estão em preço dinâmico; é a única forma de a gente saber. Então, não tem como avisar com antecedência, até porque é por demanda; se de repente acontece vira preço dinâmico. Pra ficar mais claro, tem trinta pessoas chamando em um bairro e só dez motoristas, aí eles colocam o preço dinâmico. O que acontece é que às vezes a gente sabe que vai ter por lógica: tem uma lógica em um jogo Corinthians e Ponte [e] eu sei que vai ter vinte mil pessoas saindo de lá (Bruno, 10 de agosto de 2018).

Observa-se que os(as) motoristas procuram por locais vigendo o preço dinâmico na esperança de ganhar mais dinheiro com uma corrida, porém, na prática o deslocamento até os locais "avermelhados" nem sempre é uma boa estratégia, conforme relata outro entrevistado:

É o momento que gostamos de trabalhar porque ganhamos mais com a corrida. O preço dinâmico é para atrair motoristas para o local onde não tem motorista suficiente, porém pode ser uma armadilha. Vamos supor que em Barão Geraldo está pagando 4x o valor da corrida, você sai lá do aeroporto para tentar pegar este preço dinâmico, aí quando você chega em Barão acaba o preço dinâmico e você pega uma corrida de 5 reais. Você gastou e não ganhou (Samuel, 24 de abril de 2018).

Figura 2 - Locais em preço dinâmico

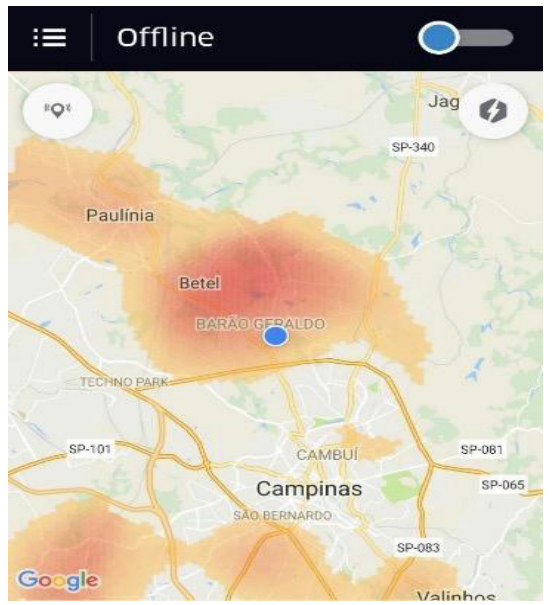

Fonte: Entrevistado da pesquisa "As ilusões da uberização".

A análise realizada por Diakopoulos (2015) indica que a tarifa dinâmica não faz um maior número de motoristas ficarem online, mas uma redistribuição dos(as) que já estavam trabalhando pelas ruas das cidades, diminuindo o tempo de espera em algumas regióes e aumentando em outras. 
Dessa forma, este mecanismo não atua como mero equilibrador entre oferta e demanda, como quer fazer crer a empresa, mas como uma ação visando o direcionamento dos(as) motoristas, levando-os(as) a trabalharem nos locais indicados por ela (MODA, 2020).

Para além do preço dinâmico, verificamos na gestão gamificada a presença de bonificaçôes, promoçóes e desafios. Os ex-empregados da empresa Uber, em Inquérito Civil do Ministério Público do Trabalho (MPT) ${ }^{12}$, quando questionados sobre premiaçóes responderam que existe o bônus para indicações de novos motoristas "tanto o motorista Uber que indicou quanto o ativado ganhavam um 'bônus' em dinheiro; que essa promoção era recorrente" (Saadi Alves de Aquino, coordenador de operaçóes, BRASIL, 2016, p. 170). Em depoimento judicial, o ex-coordenador de operaçóes da Uber afirmou que, além do "salário" pago semanalmente para os motoristas, a empresa ainda possui um sistema de premiação:

[...] que próximo ao Carnaval, por exemplo, o motorista ativado que completasse 50 viagens em 3 meses ganharia $\mathrm{R} \$ 1.000,00$ (mil reais); [...] que no dia do protesto do taxista, no início de 2016, a empresa investigada já sabia que faltariam motoristas na cidade então programou uma promoção especial para o motorista que consiste em cumprir alguns requisitos, por exemplo, ficar online 8 ou mais horas, completar 10 ou mais viagens e ter uma média de nota acima de 4,7 e, então, o motorista ganharia 50\% a mais de todas as viagens completadas nesse período e com esse padrão [...] (Saadi Alves de Aquino, coordenador de operaçōes).

Figura 3 - Desafio Natal e Ano Novo

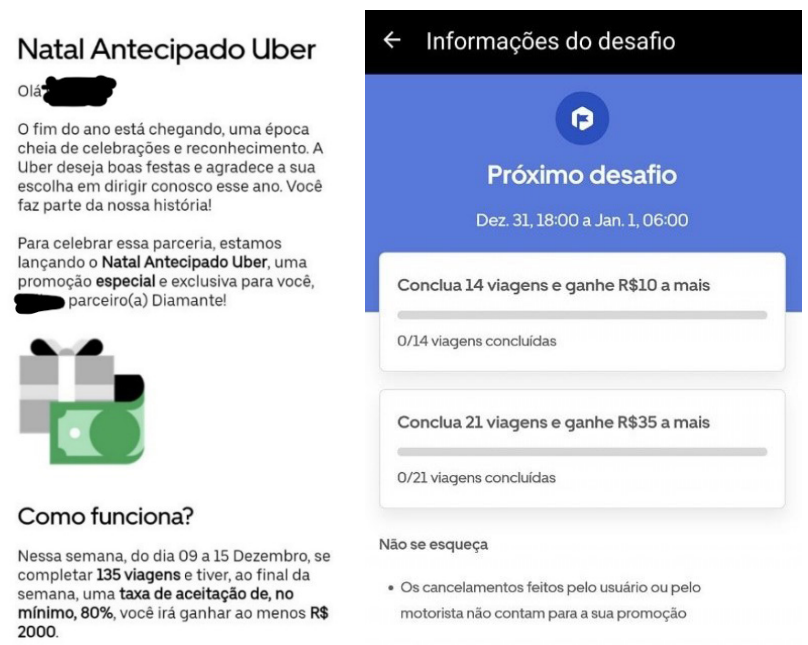

Fonte: Entrevistado da pesquisa "As ilusões da uberização".

Confirmando a política de incentivos mediante o próprio algoritmo - sistema que mostra os ganhos atuais e projeta quais seriam os futuros -, explicou o ex-gerente de operaçóes que tais

\footnotetext{
12 Em 14 de março de 2016, o Ministério Público do Trabalho da $1^{\text {a }}$ Região recebeu denúncia sigilosa contendo a seguinte notícia de fato: "os mais de mil motoristas da Uber estão sem amparo jurídico, a empresa não cumpre a lei". Tendo em vista que a falta de registro de motoristas por empresa que fornece transporte individual de passageiros ofende a ordem jurídica e constitucional, foi instaurado o Inquérito Civil n. 001417.2016.01.000/6.55. No curso da investigação, o Ministério Público do Trabalho, por meio da Procuradoria Regional do Trabalho da $1^{\text {a }}$ Regiáo, intimou alguns ex-empregados da Uber do Brasil Tecnologia Ltda., a fim de instruir o procedimento investigatório e averiguar possíveis ilícitos trabalhistas praticados no território brasileiro.
} 
mecanismos incentivam o(a) motorista a não desligar o aplicativo. Em suas palavras, tais incentivos podem parecer "bobos", mas "funcionam realmente, acaba virando um cassino" (BRASIL, 2016, p. 171) e os(as) motoristas ficam cada vez mais tentados a ficar mais horas trabalhando.

Tais mensagens possuem a intenção de explorar a preocupação das pessoas com os objetivos, induzindo os(as) motoristas a dirigirem por mais tempo. Chelsea Howe (apud SCHEIBER, 2017, online) argumenta que "a motivação internalizada é o tipo mais poderoso". Scheiber (2017) afirma que a estratégia de estabelecer metas de lucro tem como base um algoritmo semelhante ao recurso da Netflix, que reproduz o próximo episódio de forma automática. Dessa forma, o motorista recebe a próxima oportunidade antes mesmo de terminar sua corrida atual.

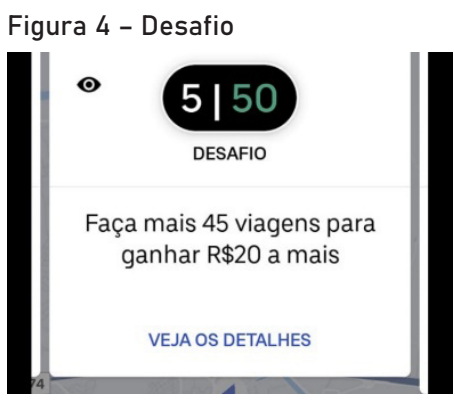

Fonte: Entrevistado da pesquisa "As ilusões da uberização".

Mesmo que, às vezes, construídas como metas quase inatingíveis, o(a) trabalhador(a) segue conectado(a) e ligado(a) no seu game/labor. Eli Solomon, motorista norte americano veterano da Uber, ao entrevistador Scheiber, disse que, ocasionalmente, teve que lutar contra o impulso de trabalhar depois de dar uma olhada em seus dados. Observou Scheiber (2017) que, em suas mensagens para os motoristas, a Uber incluía um gráfico de um indicador de motor com uma agulha que se aproximava tentadoramente de um sinal de dólar. Todas essas métricas podem estimular os impulsos competitivos que incitam ao jogo compulsivo.

As cores e o princípio cromático, de acordo com Leme (2020), também teriam o seu papel na construção de realidades sedutoras aos(as) trabalhadores(as). Possuindo aptidão para gerar efeitos psicológicos nas pessoas, influenciando o psiquismo humano com sua eficiência no domínio estético. A autora relembra a afirmação de Goethe que a cor ocupa lugar destacado entre os "fenômenos naturais primários", pois cada uma produz "um efeito específico sobre o homem, revelando assim sua presença tanto na retina como na alma" (GOETHE, 1810 apud LEME, 2020). Pode-se deduzir que "a cor pode ser usada para determinados fins sensíveis, morais estéticos" (PEDROSA, 1982 apud LEME, 2020). As cores das propagandas, da logomarca e do aplicativo são escolhidas para seduzir. O azul, por exemplo, foi a cor originalmente escolhida para ser a logomarca da Uber, além de representar o ícone da tecnologia. Esse azul representaria a "tranquilidade" (LEME, 2020).

Por conseguinte, a empresa Uber se utiliza técnicas do Neuromarketing, da ciência comportamental, da teoria das cores e dos princípios cromáticos para capturar a subjetividade, a fim de atrair, de maneira sutil, uma multidão de trabalhadores(as) (LEME, 2020).

As entrevistas a seguir demonstram a estratégia de engajar subjetivamente os(as) trabalhadores(as) através da gamificação e como os aspectos gerenciais são internalizados por eles(as):

Tem vez que já estou cansado, mas se recebo uma promoção, é uma boa oportunidade. Não penso muito no cansaço. Simplesmente vou (Danilo, 27 de abril de 2018). 
A gente sempre acha que pode ganhar um pouco a mais. E continua mais um pouquinho (Lucas, 27 de abril de 2018).

Quando o valor é baixo, não vale a pena. Quando o valor é maior, aí vale a pena continuar (Olavo, 27 de abril de 2018).

Verificamos que a liberdade de simplesmente parar o trabalho, é objeto de manipulação psíquica pela Uber, demonstrando uma espécie de "subordinação psíquica" ou "subordinação psicológica". O excerto de entrevista abaixo traz uma importante revelação sobre a subjetividade que é tocada:

V.V.C.: E subordinação? Existe?

Bernardo: Não, não existe um chefe mandando, eu não respondo para ninguém, tenho controle do meu horário. Não devo satisfação.

V.V.C.: Então você entende subordinação como dar satisfaçóes a alguém e não ter controle?

Bernardo: Isso. Graças a Deus tenho autonomia e liberdade total (Bernardo, 25 de abril de 2018).

O entrevistado louva a Deus por ter "autonomia e liberdade total". O ato de jogar traz, como referencial principal, a sensação de liberdade (HUIZINGA, 1949). Oportunas as reflexões do filósofo sul-coreano, Byung-Chul Han (2015), influenciado por Michel Foucault e Martin Heidegger, que estuda a estrutura de dominação neoliberal:

O regime neoliberal pressupõe as emoções como recursos para aumentar a produtividade e o rendimento. A partir de um determinado nível de produção, a racionalidade, que representa o meio da sociedade disciplinar, depara com os seus limites. A racionalidade é percebida como coação, como obstáculo. De súbito, tem efeitos rígidos e inflexíveis. Substituindo-a, entra em cena a emocionalidade, que tem curso paralelamente ao sentimento de liberdade, da livre realização da personalidade. Ser livre acaba por significar dar livre curso às emoçóes. $\mathbf{O}$ capitalismo da emoçáo serve-se da liberdade. A emoçáo é celebrada como uma expressáo da subjetividade livre. A técnica do poder neoliberal explora essa subjetividade livre. (HAN, 2015, p. 55. grifo nosso).

O capitalismo, munido de ferramentas tecnológicas, articula uma nova modalidade de exploração, pela captura dessas individuaçôes. Boltanski e Chiapello (2005) mencionam haver um "novo espírito do capitalismo", que incorpora o trabalho como atrativo e divertido, calcado na autonomia individual dos participantes.

Ao encontro do "novo espírito do capitalismo" o modelo de gestão gamificada opera por uma lógica sugestiva e sedutora. A subjetividade do(a) trabalhador(a) é capturada, na medida em que este(a) se vê como se fizesse parte de um jogo de videogame, impulsionado, por imagens, sons, cores, frases, incentivos gráficos luminosos, brilhantes e coloridos, a continuar apertando o botão e aceitando as corridas, sem ter sequer o tempo de analisar o custo versus o benefício daquele trabalho (LEME, 2020): "A coisa toda é como um videogame", disse o entrevistado Eli Solomon. 


\section{O QUE HÁ DE NOVO NA GESTÃO GAMIFICADA DO TRABALHO?}

A gestáo gamificada não se reduz às tarifas dinâmicas, bônus, prêmios, mas inclui ainda as formas de punição e sanção. Nas oitivas do Inquérito Civil do MPT, os ex-empregados da Uber fizeram revelaçôes sobre a empresa como a utilização da antiga técnica de gestão chamada carrots and sticks, consistente em premiar e, ao mesmo tempo punir. A expressão carrot and stick, ou, traduzindo literalmente, "cenoura e vara (porrete)" é usada para descrever uma situação em que, para fazer alguém trabalhar mais ou alcançar outro resultado desejado, são oferecidas recompensas - e, ao mesmo tempo, são feitas ameaças de puniçóes. Nesta metáfora, a cenoura seria a recompensa, e a vara (o porrete) a ameaça de punição. Por essa técnica, portanto, os que seguissem a programação receberiam premiaçóes ou bonificaçóes; aqueles(as) que náo seguissem os comandos e objetivos seriam punidos (suspensos, bloqueados, expulsos). Exemplificaram:

[...] são exemplos de campanhas de "carrot"; que outras formas eram chamadas stick, que é uma forma de ameaça em que não se dá qualquer bônus mas avisa, por email, que se o candidato não completar a ativação rapidamente, perderá as etapas do processo já realizadas; ou seja, envia-se um email, por exemplo, com a ideia: complete sua ativação até sexta-feira, ou não será mais ativado na plataforma (Saadi Alves de Aquino, coordenador de operaçóes, Rio de Janeiro, 2016)

[...] internamente se falava no sistema de 'carrots' e 'sticks'; que o sistema de pagamento de incentivos era "carrots", sobre o controle de qualidade; que nos documentos internos e e-mails usava-se a expressão "stick" para identificar medidas de controle de qualidade; que o processo de controle de qualidade consistia em garantir que somente motoristas acima de determinado nível mínimo de qualidade ficassem, baseado na avaliação média do motorista dada pelos clientes; (...) bloqueava o acesso à plataforma desses motoristas, enviando comunicado ao motorista dizendo que estaria bloqueado por esse motivo (Augusto César, gerente de operaçôes e logística, Rio de Janeiro, 2016).

Referida técnica foi objeto de estudos e publicações que remontam aos anos 1800. Autores escreveram em referência a um desenho da época que retratava uma corrida entre cavaleiros de burros, com o jóquei perdedor usando a estratégia de bater em seu animal com galhos para impulsioná-lo para frente, enquanto o vencedor da corrida usava a tática de segurar uma vara com uma isca, para atrair o animal. No ano de 1948, após a 2a Guerra Mundial, a tática ligava-se à ideia de estimular a produtividade. Há relatos de uso também do carrots and sticks como método stalinista durante a Guerra Fria (SCHMALTZ, 2016).

Para além da técnica carrots and sticks utilizada pela Uber, encontramos entre os(as) entregadores(as) o chamado "Bloqueio Branco". Paulo Galo, líder dos "Entregadores Antifascistas", assim o explicou em uma entrevista: "o cadastro fica ativo, você fica online, mas não recebe nenhum pedido, nada chega para você. E nem importa onde esteja, pode ficar circulando que a empresa não vai te passar nenhuma entrega" (apud SINPOSBA, 2020, online). Trata-se de espécie de castigo tácito - não oficial e de uso não admitido pelos aplicativos - que é aplicado aos(as) trabalhadores(as) que se organizam politicamente enquanto classe, ou que demonstram publicamente contrariedade aos termos estabelecidos pelas empresas. Nessa modalidade de bloqueio, o(a) entregador(a) não é notificado(a) da punição, deixando de receber pedidos e oportunidades de entrega em um intervalo de tempo. 
As empresas plataformas mesclam metas que são alcançáveis pelos(as) trabalhadores(as), motivando-os(as) a seguirem trabalhando, com metas impossíveis, que também não são uma novidade no capitalismo. Essa tática já era adotada por empresas tradicionais, que definiam metas impossíveis de serem atingidas, forçando a intensificação do trabalho e o aumento da produção.

A vivência dos(as) trabalhadores(as), hoje, nos revela a existência de táticas das empresas que impedem o recebimento do prêmio, apesar do esforço a mais empreendido. Os relatos dos(as) trabalhadores(as) nos grupos de Facebook nos mostram, por exemplo, que se o prêmio define a necessidade de realização de 50 corridas em um determinado período de tempo, quando o(a) trabalhador(a) se aproxima da meta há uma redução do número de chamadas, causando um sentimento nos(as) trabalhadores(as) de frustração, decepção, revolta, entre outros sentimentos desagradáveis.

As novas tecnologias não só potencializam a gestão gamificada do trabalho, como também permitem que as plataformas, que são "alimentadas por dados, automatizadas e organizadas por meio de algoritmos” (VAN DIJCK; POELL, T.; DE WAAL, 2018, p. 9), não sejam responsabilizadas por esses eventos que, na verdade, são decisóes. O gerenciamento algorítmico é caracterizado pela implementação automática de decisóes algorítmicas (MÖHLMANN; ZALMANSON, 2017). O trabalhador culpa o algoritmo ${ }^{13}$ pelos acontecimentos, por compreendê-lo como neutro, a despeito de serem criados pelas empresas que determinam unilateralmente as regras (VIDIGAL, 2020).

Mazzotti (2017) alerta que o algoritmo é considerado invisível, apesar de integrado em diversos aspectos do cotidiano das pessoas, torna-se uma caixa preta e é afastado do escrutínio do público, passando a ser encarado como um elemento natural. Dessa forma, a percepção de que se está sendo controlado é muito sutil, o que gera dificuldade de se reconhecer o controle. Portanto, é necessário o exercício de ressaltar que o algoritmo de neutro não tem nada, para afastar o que Taina Bucher (2017) chama de imaginário algorítmico de neutralidade e objetividade.

A existência dos algoritmos vai além da concepção instrumental sugerida pela retórica institucional da plataforma. Os algoritmos, como qualquer outra tecnologia, são produzidos a partir do trabalho humano para empresas de tecnologia e ao mesmo tempo, "também são resultados das interaçôes das pessoas comuns com esses algoritmos” (GROHMANN, 2020, p. 97). Na verdade, trata-se de opinião embutida em matemática, escreveu Cathy O’Neil (2016) afirmando que todo algoritmo, em alguma medida, carrega em si os valores e as opinióes de quem o construiu, em um processo de reprodução de certos comportamentos.

Ao desenvolver o conceito de capitalismo de vigilância, Shoshana Zuboff (2018) aborda a combinação entre vigilância, perda da privacidade e controle. Nos ambientes gamificados os acessos e as açôes realizadas são registradas com frequência, assim como acontece nas atividades de navegação realizadas em sites da Internet. O ciberespaço, frequentemente visto como um espaço de liberdade, transforma-se em um local onde todas as açôes são registradas. Talvez seja, conforme mencionado por Santos e Ferreira (2008), “o espaço mais controlado que o ser humano já construiu”. A coleta de dados é surpreendente e, a esse despeito, não há controle trabalhista sobre a questão (SCHEIBER, 2017). Estes dados são utilizados de forma obscura e as regras do "jogo" não são acordadas com os(as) trabalhadores(as).

Verificamos, portanto, que nas práticas de gerenciamento algorítmico, os trabalhadores interagem com um "sistema" em vez de humanos. Em muitos casos, o sistema tem menos transparência

13 Segundo Kleinberg "pode-se pensar informalmente um algoritmo como um passo a passo, um conjunto de instruçōes, expressado em uma linguagem estilizada, para a resoluçáo de um problema” (KLEINBERG, 2008. p. 1). Ele transforma "dados em resultados desejados" (GILLESPIE, 2018). 
e os trabalhadores não têm conhecimento do conjunto de regras que governam os algoritmos (MÖHLMANN; ZALMANSON, 2017). O algoritmo aparece como executor da vontade e valores da empresas, um intermediário entre a plataforma e os(as) trabalhadores(as). Em tempos de arquitetura da informação ${ }^{14}$, (e o controle está aí, na maneira como a informação é produzida e manipulada pela empresa), principalmente aquele que está sendo controlado, não enxerga a pessoa do controlador, podendo portanto, compreender a técnica como neutra. Nesse sentido, há uma novidade em relação aos moldes fordistas que contava com a presença de um chefe físico gerenciando o trabalho, cujas ordens eram facilmente identificáveis.

\section{O NOVO PEDE O VELHO:}

\section{A IMBRICAÇÃO DA GAMIFICAÇÃO COM O SALÁRIO POR PEÇA}

Os(as) trabalhadores(as) recebem remuneração por cada entrega/corrida realizada. Trata-se do "salário" por unidade de obra. Retendo o que denomina "taxa de serviço" sobre o preço das corridas, a Uber utiliza-se do mais tradicional modo capitalista de produção e reprodução de riqueza - a extração do excedente da força de trabalho. A taxa cobrada é calculada pelo próprio aplicativo e leva em consideração a quilometragem percorrida e o tempo permanecido dentro do automóvel. A empresa não fornece a metodologia utilizada para a fixação dos valores do serviço, não apontado as variáveis utilizadas e o funcionamento de seu algoritmo. Entretanto, incontroverso que este sistema é determinado unilateralmente por ela.

A empresa, no mês de julho de 2018, implementou um novo modelo pelo qual o passageiro continuará pagando pela estimativa da viagem, calculada antes de o trajeto ser percorrido (NEGRÃO, 2018). No entanto, o(a) motorista é remunerado(a) pela distância e tempo reais do percurso - não em porcentagem. Até então, motoristas do UberX e UberSelect tinham que pagar taxa fixa de $25 \%$, enquanto a UberBlack cobrava $20 \%$. No novo sistema de cobrança, a apelidada "taxa flutuante" pelos motoristas, vem causando discórdia, conforme narra o entrevistado: "Hoje com a taxa flutuante pode ser cobrado do motorista de $25 \%$ a $50 \%$. Parece zueira, mas náo é, daqui a pouco a gente vai tá pagando pra trabalhar" (Bruno, 10 de agosto de 2018).

O cálculo da remuneração líquida percebida pelos(as) trabalhadores(as) é realizado pelo desconto automático dessa taxa. Ainda, são obrigados(as) a descontar, da parcela sobre o valor que é depositado pelas empresas em suas contas correntes, todos os gastos inerentes ao serviço de transporte, como combustível, manutenção, seguro, taxas, impostos sobre os veículos/motocicletas e licenciamentos, além dos gastos com sua automanutenção, como alimentação, saúde e seguro de vida (VIDIGAL, 2020). Na pandemia, o fato de os(as) trabalhadores(as), na maioria das vezes terem de custear as medidas e proteção acaba por reduzir ainda mais a sua remuneração (ABILIO et al., 2020).

Esse modelo remuneratório reedita uma forma antiga de pagamento: o salário por peça que, a despeito de não ser hegemônico na sociedade contemporânea, seguiu existindo em alguns ramos produtivos em coexistência com o salário por tempo. A gestáo por plataformas ao automatizar o controle, permite a proliferação do trabalho por peça.

Em "O Capital" pode-se encontrar pistas preciosas para entender tanto a dialética do trabalho, quanto a problematização do salário por peça: a remuneração do trabalhador depende não de sua

14 Saul Wurman (1997) definiu Arquitetura da Informação como sendo a ciência e a arte de criar instruções para espaços organizados. 
jornada, mas de sua produção. No século XIX, Marx (2013) já assinalava a tendência a uma opacidade ainda maior da relação entre capital e trabalho quando mediada pela remuneraçáo por peça.

A passagem da medida do salário por tempo de trabalho para o salário por peça materializa uma transferência do controle sobre o tempo e a produtividade do trabalho para o próprio trabalhador. Com o pagamento por peça o custo da ociosidade é jogado ao(a) trabalhador(a). Marx (2013) explica que ao remunerar não pelo tempo, mas pela quantidade produzida, se favorece um aumento tanto da extensão do tempo de trabalho como de sua intensidade:

Dado o salário por peça, é naturalmente do interesse pessoal do trabalhador aplicar sua força de trabalho o mais intensamente possível, o que facilita ao capitalista elevar o grau normal de intensidade. Do mesmo modo, é interesse pessoal do trabalhador prolongar a jornada de trabalho, pois com isso sobe seu salário diário ou semanal (MARX, 2013, p. 141).

Dessa forma, a intensificação do trabalho, objetivo de toda gestão capitalista, seria obtida através do salário por peça. O salário por peça permite ao capitalista maior ganho de produtividade. No trabalho plataformizado, a exigência de produtividade pode ser cumprida através de metas disfarçadas de gamificação. A partir das entrevistas realizadas nas pesquisas, conseguimos verificar que trabalham por metas individuais pré-definidas e só param quando a alcançam. Em seu bojo está a terceirização de parte do gerenciamento do trabalho para o(a) próprio(a) trabalhador(a).

Callum Cant (2019) destaca no mesmo sentido apresentado por Marx que o salário por peça força $\mathrm{o}(\mathrm{a})$ trabalhador(a) a auto gerenciar sua produtividade. $\mathrm{O}$ autor, recorrendo à sua própria experiência de ciclista entregador, descreve como esse autogerenciamento e a consequente auto intensificação do trabalho ocorriam na prática. Como há uma considerável imprevisibilidade na demanda e nos pedidos que cada entregador(a) individualmente irá receber, nos horários sabidamente de pico de demanda o(a) entregador(a) tende a acelerar e a não fazer pausas, de modo a realizar o máximo de entregas possível nesse horário, tentando compensar assim o baixo ganho por hora nos demais períodos (CANT, 2019).

Trata-se, portanto, de uma espécie de internalização do controle da jornada de trabalho, que se efetiva nessa indistinção entre tempo de trabalho e de não-trabalho, ou no caso desses(as) trabalhadores(as), no "tornar todo tempo potencial tempo de trabalho" (ABÍLIO, 2011). Na definição de plenitude do trabalho abstrato, Oliveira (2013) refere-se aos ganhos da constante "luta do capital para reduzir a porosidade ${ }^{15}$ do trabalho". O mundo do trabalho passa por uma intensificação generalizada e problematizá-la traz a exploraçáo ao debate. Como destaca Dal Rosso (2008, p. 71), a exploraçáo do trabalho, na modernidade, passa a ser cada vez mais intensa: "o tempo livre, o tempo de não trabalho, passa a ser engolido pelo trabalho". A fronteira entre tempo de vida e o tempo dedicado a atividades de trabalho vem se tornando cada vez mais tênue e embaçada. O tempo individual privado e a vida própria de cada um não mais existem como algo “à parte” (KIRKPATRICK, 2015).

Conclui-se que esse modelo de organização e gestão acaba por autorizar os(as) trabalhadores(as) a naturalizar o seu cotidiano de excesso de trabalho, trabalhar para uma plataforma digital, para a maioria deles(as), é sinônimo de jornadas de trabalho estendidas.

15 Com relaçáo à porosidade, Dal Rosso estabelece que “a jornada compreende em seu interior duas realidades: momento
de trabalho e de não-trabalho. Dentro da jornada, estes últimos formam aquilo que Marx chama de 'porosidade' do trabalho. Du-
rante os tempos mortos, os 'porosos', o trabalhador não trabalha e não produz valor. Como o trabalho assalariado é heterônomo,
o empregado procura aumentar os tempos de náo trabalho e assim diminuir seu próprio desgaste." (DAL ROSSO, 2008, p. 47). 
Cant (2019) também destaca que o salário por peça pode ser um obstáculo à solidariedade coletiva, uma vez que os(as) entregadores(as) de certa forma passam a competir pelos pedidos. Marx (2013) já indicava que o salário por peça favorece a concorrência entre os trabalhadores e de uns contra os outros. O salário por peça cria a competição permanente entre os trabalhadores. No excerto abaixo podemos verificar a competição entre eles e de uns contra os outros, em moldes atuais, na imbricação da gamificação com o salário por peça:

Danilo: Eu e uns parceiros apostamos quem bate a meta mais rápido.

VVC: Vocês apostam entre vocês? Apostam dinheiro?

Danilo: Sim, mas não é muita coisa. Um trocado, senão fica puxado para quem perde.

VVC: E como vocês combinam tudo?

Danilo: Pelo whats. A gente pega o mesmo desafio e ganha quem completa primeiro. No feriado passado, rolou um.

VVC: Você ganhou?

Danilo: Perdi! (Danilo, 27 de abril de 2018).

Marx (2013) ainda ressaltava que o salário por peça favorece o desenvolvimento da individualidade, do sentimento de liberdade, de autonomia e de autodeterminação dos trabalhadores. Nesse sentido, Callum Cant (2019) apresenta o salário por peça como parte constituinte e fundamental do sistema de controle do trabalho, pois este permitiria que as empresas por aplicativo dispensassem um sistema de disciplina do trabalho com supervisores humanos. Para o autor, essa forma de salário favorece que os trabalhadores se vejam como seus próprios patróes, conforme é do interesse dos capitalistas que exploram esse trabalho e a classificação dos trabalhadores como autônomos não seria meramente uma forma de evasão dos direitos trabalhistas e de seus respectivos custos por parte do capitalista. O status de trabalhador(a) autônomo(a $)^{16}$ seria fundamental para permitir o sistema de salário por peça, sem nenhum salário fixo e sem necessidade do pagamento de um salário mínimo, sendo assim um fundamento necessário ao próprio sistema de controle e gestão do trabalho.

De acordo com Cant (2019), o sistema de controle das empresas por aplicativos, baseado no salário por peça, força os(as) trabalhadores(as) a assumirem cada vez mais riscos de modo aumentarem sua remuneração. Intensificação do trabalho essa, como alerta, que pode ser fatal, uma vez que isso resulta em entregas mais rápidas. As pesquisas demonstram que premiar e estimular a velocidade no atendimento dos motoristas/motoboys é um fator associado aos acidentes de trânsito (RODRIGUES; AMANCIO, 2021).

A etnografia realizada por nossa pesquisa nos grupos de whatsapp aponta que a palavra "promo" é uma das mais constantes nas conversas entre os(as) entregadores(as). É comum perguntarem uns(umas) aos(as) outros(as) se está vigendo alguma promoção. Foi percebido pelo(a) trabalhador(a)

16 Não se descura que a qualificação jurídica desses(as) trabalhadores(as) é objeto de disputa na Justiça do Trabalho, e da existência de decisóes que concederam o vínculo empregatício aos(às) plataformizados(as), a esse despeito, a atual classificação difundida majoritariamente em nosso ordenamento é de trabalhadores(as) autônomos(as). 
quais são os períodos frequentes que as promoçôes existem: "Feriado é sempre bom, dia das máes, dia dos namorados. Sempre promoção". São frequentes as promoçôes de R \$ 2,00 (dois reais), por rota das 19:30 às 21:59, em dias chuvosos, que é outro fator associado aos acidentes de trânsito.

Uma das consequências de sofrer um acidente é não poder trabalhar, e nesse modelo laboral, se não trabalhar, não ganha. Há relatos, ainda, de trabalhadores(as) acidentados(as) que foram suspensos(as) e desligados(as) das plataformas. A pausa forçada no "jogo", então escancara a realidade: trata-se de um trabalho altamente explorado, no qual os(as) trabalhadores(as) desprotegidos(as) de direitos trabalhistas e sociais "jogam” pela sobrevivência.

\section{CONSIDERAÇÕES FINAIS: 0 JOGO DA VIDA}

Uma regulação protetiva eficaz só pode vir do entendimento do que é e de como se opera a gestão gamificada. A gestão gamificada é realizada a partir da imbricação de lógicas antigas como o pagamento por trabalho feito- o salário por peça-, a técnica de gestão carrots and sticks, com as novas tecnologias, os algoritmos, as técnicas de design virtuais, entre outras.

No contexto do trabalho plataformizado, o uso da gamificação se alinha com a estratégia capitalista de incorporar o tempo de vida como atividade produtiva ao sistema, intensificando e estendendo o tempo de trabalho. O que podemos observar é que a gestão gamificada e o gerenciamento algorítmico atendem aos anseios do capital e do capitalista, cujo objetivo é o lucro.

"Tenho muito azar mesmo" (Danilo, 27 de abril de 2018), se lamentou um dos entrevistados da pesquisa, se referindo ao fato de que quando estava chegando perto da meta estabelecida, não ter tido a "sorte" de ter recebido mais chamadas para conseguir a bonificação. Sorte ou azar não se combatem e talvez não se possa resistir ao que é aleatório na vida. Entretanto, a gestáo gamificada do trabalho não é um jogo de sorte ou azar. $\mathrm{O}$ algoritmo não é aleatório, neutro ou etéreo. Trata-se de um jogo com regras pré determinadas, definidas de forma unilateral pelas empresas-plataformas tendo como objetivo estimular os(as) trabalhadores(as) a ficarem disponíveis para o trabalho, o máximo de tempo. Um jogo com regras de cartas marcadas para o capitalista vencer e o trabalhador perder. Enquanto o "jogo" continua desregulado, os(as) trabalhadores(as) desempenham suas atividades sem parar, desprotegidos(as), sendo interrompidos(as) apenas por doenças laborais e acidentes de trabalho - que por vezes, ceifam suas vidas. O game over: sem vida, não há jogo.

\section{REFERÊNCIAS}

ABÍLIO, Ludmila Costhek; ALMEIDA, Paulo Freitas; AMORIM, Henrique; CARDOSO, Ana Claudia Moreira; FONSECA, Vanessa Patriota da; KALIL, Renan Bernardi; MACHADO, Sidnei. Condiçóes de trabalho de entregadores via plataforma digital durante a Covid-19. Revista Jurídica Trabalho e Desenvolvimento Humano, Campinas, Edição Especial -Dossiê Covid-19, p. 1-21, 2020.

ALVES, Giovanni. Trabalho, subjetividade e capitalismo manipulatório: o novo metabolismo social do trabalho e a precarização do homem que trabalha. Revista Eletrônica da RET - Rede de Estudos do Trabalho, Marília, ano IV, n. 8, p. 1-31, 2011.

ANTUNES, Ricardo. Trabalho uberizado e capitalismo virótico: entrevista com Ricardo Antunes. Digilabour, 2020. Disponível em: https://digilabour.com.br/2020/06/14/trabalho-uberizado-e-capitalismo-virotico-entrevista-com-ricardo-antunes. Acesso em: 20 out. 2020.

BOLTANSKI, Luc; CHIAPELLO, Ève. O novo espírito do capitalismo. São Paulo: Martins Fontes, 2005. 
BUCHER, T. The Algorithmic Imaginary: exploring the ordinary affects of Facebook algorithms. Information, Communication \& Society, [s.l.], vol. 20, n. 1, p. 30-44, 2017.

BRASIL. Procuradoria Regional do Trabalho da $1^{\text {a }}$ Região. Inquérito Civil n. 001417.2016.01.000-6. 22 de março de 2016.

CANT, Callum. Riding for Deliveroo: Resistance in the New Economy. Cambridge: Polity Press, 2019.

CASTRO, Viviane Vidigal. As ilusóes da uberizaçáo: um estudo à luz da experiência de motoristas Uber. 303 f. 2020. Dissertação (Mestrado em Sociologia) - Instituto de Filosofia e Ciências Humanas, Universidade Estadual de Campinas, Campinas/SP, 2020.

DAL ROSSO, Sadi. Mais trabalho!: a intensificaçáo do labor na sociedade contemporânea. São Paulo: Boitempo, 2008.

DETERDING, Sebastian; Dixon, Dan; Khaled, Rilla; Nacke, Lennart. From game design elements to gamefulness: defining gamification. Proceedings of the 15th International Academic MindTrek Conference: Envisioning Future Media Environments. ACM, 2011.

DIAKOPOULOS, Nicholas. How Uber surge pricing really works. The Washington Post, 2015. Disponível em: <https:/www.washingtonpost.com/news/wonk/wp/2015/04/17/how-uber-surge-pricing-really-works/?noredirect=on\&utm_term=.6f682adc2568>. Acesso em: 10 jun. 2019.

FERRARA, John. Games for persuasion argumentation, procedurality, and the lie of gamification. Games and Culture, [s.l.], vol. 8, n. 4, p. 289-304, 2013.

DUJARIER, Marie-Anne, Le management désincarné, Paris, La Découverte, 2015, p. 218

GILLESPIE, T. A relevância dos algoritmos. Parágrafo, [s.l.], vol. 6, n. 1, p. 97, jan./abr. 2018

GROHMANN, R. Plataformização do trabalho: características e alternativas. In: ANTUNES, Ricardo (org.). Uberizaçáo, trabalho digital e Indústria 4.0. São Paulo: Boitempo, 2020. p.

HAN, Byung-Chul. Psicopolítica. Barcelona: Herder, 2015

HUIZINGA, Johan. Homo Ludens. São Paulo: Editora Perspectiva, 1949.

HUOTARI, Kai; HAMARI, Juho. "Gamification" From the Perspective of Service Marketing. Proceedings of the 2011 annual conference extended abstracts on Human factors in computing systems - CHI EA'11, Vancouver, Canada, p. 11-15, 2012.

KAPP, Karl. M. The gamification of learning and instruction: game-based methods and strategies for training and education. San Francisco, John Willey \& Sons, Inc. 2012.

KIRKPATRICK, Graeme. Ludefaction: fracking of the radical imaginary. Games and Culture, [s.l.], vol. 10, n. 6, p. 1-18, 2015.

KLEINBERG, Jon. The Mathematics of Algorithm Design. Princeton Companion to Mathematics, Princeton Univ. Press, p.1-8, 2008. Disponível em:<https://www.cs.cornell.edu/home/kleinber/pcm.pdf>. Acesso em: 08 nov. 2017. 
LEME, Ana Carolina Reis Paes. Neuromarketing e sedução dos trabalhadores: o caso Uber. In: CARELLI, Rodrigo de Lacerda; CAVALCANTI, Tiago Muniz; FONSECA, Vanessa Patriota. Futuro do trabalho: os efeitos da revoluçáo digital na sociedade. Brasília : ESMPU, 2020.472 p.

MALABY, Thomas. Beyond Play: A New Approach to Games. Games and Culture, vol. 2, p. 95-113, 2007.

MARX, Karl. O capital: crítica da economia política. Livro I: o processo de produção do capital. São Paulo: Boitempo, 2013.

MAZZOTTI, Massimo. Algorithmic life. In: PRIDMORE-BROWN, Michele; CROCKETT, Julien. The digital revolution: debating the promises and perils of the Internet, automation, and algorithmic lives in the last years of the Obama Administration. Los Angeles: Los Angeles Review of Books, 2017. p. 34-35.

MODA, Felipe Bruner. Trabalho por aplicativo: As práticas gerenciais e as condiçóes de trabalho dos motoristas da Uber. 149f. 2020. Dissertaçáo (Mestrado em Ciências Sociais) - Escola de Filosofia, Letras e Ciências Humanas, Universidade Federal do Estado de São Paulo, Guarulhos, 2020.

MÖHLMANN, Mareike; ZALMANSON, Lior. Hands on the wheel: Navigating algorithmic management and Uber drivers' autonomy. Proceedings of the International Conference on Information Systems (ICIS 2017), Seoul, South Korea, dez. 2017.

NEGRÃO, Heloísa. Uber extingue taxa fixa cobrada de motoristas. Folha de Sáo Paulo, 2 de julho de 2018. Disponível em: https://www1.folha.uol.com.br/mercado/2018/07/uber-extingue-taxa-fixa-cobrada-de-motoristas.shtml. Acesso em: 03 jul. 2018.

OHNO, Taiichi. O Sistema Toyota de Produção: além da produção em larga escala. Porto Alegre: Bookman, 1997.

OLIVEIRA, Francisco de. Crítica à razáo dualista/O Ornitorrinco. São Paulo: Boitempo, 2013.

O'NEIL, Cathy. Weapons of Math Destruction: How Big Data Increases Inequality and Threatens Democracy. Nova Iorque: Crown Books, 2016.

PEREIRA, Felipe. Entregadores protestam contra reducação de valor pago por aplicativos em SP. UOL, São Paulo, 17 abr. 2020. Disponível em: https://noticias.uol.com.br/saude/ultimas-noticias/redacao/2020/04/17/ motoboys-de-sp-protestam-contra-baixos-pagamentos-de-aplicativos-de-entrega.htm. Acesso em: 25 mai. 2020

REIS, Daniela Muradas; CORASSA, Eugênio Delmaestro. Aplicativos de transporte e plataforma de controle: o mito da tecnologia disruptiva do emprego e a subordinação por algoritmos. In: LEME, Ana Carolina Reis Paes; RODRIGUES, Bruno Alves; CHAVES JÚNIOR, José Eduardo de Resende (coord.). Tecnologias disruptivas e a exploraçáo do trabalho humano. São Paulo: LTr, 2017. p. 157-165.

Relatório Parcial de Pesquisa. ABÍLIO, Ludmila. C.; ALMEIDA, Paula. F.; AMORIM, Henrique; CARDOSO, Ana. C. M.; FONSECA, Vanessa. P.; KALIL, Renan. B.; MACHADO, Sidnei. Condiçóes de trabalho em empresas de plataforma digital: os entregadores por aplicativo durante a Covid-19. São Paulo: REMIR, 2020. 11 p. 
RIBEIRO, Gabriel. Motoristas de apps como Uber perdem até $90 \%$ das corridas e querem taxa zero. UOL, São Paulo, 31 mar. 2020. Informação disponível em: https:/www.uol.com.br/tilt/noticias/redacao/2020/03/31/motoristas-de-apps-como-uber-perdem-ate-90-das-corridas-e-querem-taxa-zero.htm. Acesso em: 30 mar. 2021.

RODRIGUES; AMANCIO. Com explosão de apps e fiscalização falha acidentes caem menos entre motociclistas em São Paulo. UOL, São Paulo. Disponível em: https://www1.folha.uol.com.br/cotidiano/2021/02/ com-explosao-de-apps-e-fiscalizacao-falha-acidentes-caem-menos-entre-motociclistas-em-sp.shtml. Acesso em: 20 mar. 2021.

RYAN, Richard; RIGBY, Scott; PRZYBYLSKI, Andrew. Motivational pull of video games: a self-determination theory approach. Motivation and Emotion, [s.l.], vol. 30, n. 4, p. 344-60, 2006.

SALEN, Katie; ZIMMERMAN, Eric. Rules of play: Game design fundamentals. London: The MIT Press, 2004.

SANTOS, Laymert Garcia dos; FERREIRA, Pedro Peixoto. A regra do jogo: desejo, servidão e controle. In: VILARES, Fábio. (org.). Novas mídias digitais: impactos políticos, econômicos e sociais. Rio de Janeiro: E-papers, 2008.

SAVIGNAC, Emmanuelle. La gamification du travail. L'ordre du jeu, Londres: ISTE éditions, 2017.

SCHEIBER, N. How Uber uses psychological tricks to push its drivers' buttons. New York Times, 2 de abril de 2017. 2017. Disponível em: https://www.nytimes.com/interactive/2017/04/02/ technology/uber-drivers-psychological-tricks.html. Acesso em: 20 jan. 2018.

SCHMALTZ, Eric. Carrots and Sticks... and Demonstrations: Yuri Andropov's failed autonomy plan for soviet Kahakhstan's Germans, 1976-1980. Journal of the American Historical Society of Germans from Russia, Lincoln, Nebraska, vol. 39, n. 3, p. 1-21, 2016.

SENNETT, Richard. A corrosáo do caráter: consequências pessoas do trabalho no novo capitalismo. Rio de Janeiro: Record, 2003.

SINPOSBA. 'É greve.' Entregadores iniciam luta por direitos e querem carteira assinada. Notícias. Disponível em: https://www.sinposba.org.br/index.php/2020/06/17/e-greve-entregadores-iniciam-luta-por-direitos-e-querem-carteira-assinada/. Acesso em: 9 jun. 2021.

STARK, Luke. "Algorithmic Labor and Information Asymmetries: A Case Study of Uber's Drivers". International Journal of Communication, vol. 10, 2016, pp. 3.758-84.

UBER, 2020. Home. Disponível em: https://www.uber.com/pt-BR/blog/campinas/perguntas-e-respostas-sobre-o-preco-dinamico/. Acesso em: 20 jan. 2021.

VAN DIJCK, José; POELL, Thomas; DE WAAL, Martjin. The Platform Society. New York: Oxford, 2018.

VIDIGAL, Viviane. Delivery viral: entre a virtualidade do pedido e a concretude da entrega. In: CASTRO, Bárbara. (org.). Covid-19 e Sociedade: ensaios sobre a experiência social da pandemia. 1ed.Campinas: IFCH, 2020. p. 278-294. 
WERBACH, Kevin. (2016). Curso: “Gamification”. Disponível em: https://www.coursera.org/course/ gamification. Acesso em: 20 mar. 2021.

WERBACH, Kevin; HUNTER, Dan. For the win: how game thinking can revolutionize your Business. Filadélfia: Wharton Digital Press, 2012.

WURMAN, Richard. Information architects. 2.ed. Lakewood: Watson-Guptill Pubns, 1997.

ZUBOFF, Shoshana. Big Other: capitalismo de vigilância e perspectivas para uma civilização de informação. In: BRUNO, Fernanda et al. (orgs.). Tecnopolíticas da vigilância: perspectivas da margem. São Paulo: Boitempo, 2018. 